\title{
Molecular cell biology and physiology of solute transport:
}

\author{
Epithelial junctions and polarity: complexes and kinases
}

\author{
Michael J. Caplan, Patricia Seo-Mayer, and Li Zhang \\ Department of Cellular and Molecular Physiology, Yale University School of Medicine, New \\ Haven, Connecticut, USA
}

\section{Abstract}

Purpose of review-An enormous body of research has been focused on exploring the mechanisms through which epithelial cells establish their characteristic polarity. It is clear that under normal circumstances cell-cell contacts mediated by the calcium-dependent adhesion proteins of the intercellular adhesion junctions are required to initiate complete polarization. Furthermore, formation of the tight, or occluding, junctions that limit paracellular permeability has long been thought to help to establish polarity by preventing the diffusion of membrane proteins between the two plasmalemmal domains. This review will discuss several selected kinases and protein complexes and highlight their relevance to transporting epithelial cell polarization.

Recent findings-Recent work has shed new light on the roles of junctional complexes in establishing and maintaining epithelial cell polarity. In addition, work from several laboratories, suggests that the formation of these junctions is tied to processes that regulate cellular energy metabolism.

Summary-Junctional complexes and energy sensing kinases constitute a novel class of machinery whose capacity to generate and modulate epithelial cell polarity is likely to have wide ranging and important physiological ramifications.

\section{Keywords}

AMP kinase; epithelia; junction; polarity

\section{Introduction}

Few cell types more elegantly embody the dictum that 'form follows function' than do those of polarized epithelia. Epithelial cells constitute the boundaries that separate an organism's extracellular fluid compartment from the external environment in which that organism exists. As such, epithelial cells must be capable of acting as the continuous physical barrier that prevents a sudden and catastrophic merger between the constituents of those two spaces. This barrier function, however, though biologically critical and mechanistically fascinating, is only the simplest of the tasks that polarized epithelial cells are called upon to perform. In fact, it is the ability of polarized epithelial cells to mediate the vectorial transport of fluid and solutes that essentially determines the composition of the organism's internal environment [1,2].

The cell surface membranes of polarized epithelial cells are divided into morphologically and compositionally distinct domains that are separated by intercellular tight junctions [3-

Correspondence to Michael J. Caplan, Department of Cellular and Molecular Physiology, Yale University School of Medicine, P.O. Box 208026, New Haven, CT 06525-8026, USA Tel: +1 203785 7316; Michael.caplan@yale.edu. 
5]. While the basolateral plasma membrane domain is in contact with the extracellular fluid compartment, the apical domain generally confronts a lumen that is often ultimately contiguous with the outside world. These two cell surface domains manifest almost completely different inventories of membrane proteins. For the purposes of this discussion, it is the polarized distribution of ion transport proteins among these portions of the epithelial plasma membrane that provides the physiological justification for epithelial polarity [2]. If ion transport proteins were not asymmetrically distributed between the surface domains of transporting epithelial cells then it would not be possible to generate and maintain the gradients of ions and nonelectrolyte solutes that are required for homeostasis. In order for the sorting mechanisms discussed above to be effective in producing the appropriate distributions of ion transport proteins among the two polarized domains of the epithelial plasma membrane, these domains must first be established and segregated from one another. Recent evidence suggests that signaling systems involved in sensing and responding to changes in cellular energy status may play a central role in this process of epithelial polarization.

\section{AMP-stimulated protein kinase: a cellular energy sensor and participant in epithelial polarization}

Epithelial cells involved in fluid and electrolyte transport are major consumers of biological energy. Most transporting epithelial cells are richly endowed with mitochondria that provide their complements of pumps with the copious quantities of ATP that they consume in order to generate the ion gradients that power transepithelial fluid and solute movement. Not surprisingly, therefore, even brief interruptions in the substrates required for ATP generation can lead to profound damage to epithelial cells, manifest in the loss of epithelial polarity and the redistribution of transport proteins [6,7].

Muscle cells are similarly prodigious users of biological energy. Recent research has shown that myocytes keep a close watch on cellular energy levels and, when these levels fall, the myocytes activate pathways that reduce nonessential energy consumption and activate alternative mechanisms for energy generation. A single enzyme known as AMP-stimulated protein kinase (AMPK) appears to measure cellular energy levels and to initiate the appropriate responses in the event of their decline $\left[8^{*}, 9^{\circ}\right]$. When ATP levels fall, AMP levels rise. AMPK is composed of three subunits $(\alpha, \beta$ and $\gamma$ ) (Fig. 1). There are two isoforms of the AMPK $\alpha$-subunit. While the $\alpha 2$ isoform is expressed predominantly in skeletal and cardiac muscle, the $\alpha 1$ isoform is found in most cell types. The $\gamma$-subunit of AMPK binds to AMP and undergoes a conformational change in response to this binding event $\left[9^{\circ}, 10\right]$. This conformational change in turn allows the $\alpha$-subunit to become a substrate for phosphorylation at Thr172 by an upstream kinase that is necessary and sufficient to activate the kinase $\alpha$-subunit's intrinsic kinase activity. It is also possible that AMP binding results in a reduction in the susceptibility of AMPK to dephosphorylation by protein phosphatases [11]. Once activated, the AMPK goes on to phosphorylate and regulate the activities of a wide variety of proteins to readjust the balance between energy production and consumption.

The best characterized of the upstream 'AMP-kinase kinases' is LKB1 [12], a kinase first identified as the product of the Peutz-Jaeger syndrome tumor suppressor gene. Mutations in the gene encoding LKB1 lead to the formation of numerous hamartomatous neoplasms [13]. It has been shown that LKB 1 is a negative regulator of the mammalian target of rapamycin (mTOR) signaling pathway through the sequential activation of AMPK and of the tuberous sclerosis complex (TSC)1/TSC2 tumor suppressor complex [14]. It is especially interesting in this context that transfection of the human colonic epithelial cell lines with cDNAs encoding co-factor polypeptides that constitutively activate LKB1 endows the transfected 
cells with the capacity to develop a polarized phenotype in the absence of cell-cell or cellmatrix contact [15]. It would appear, therefore, that LKB1 can act as a critical control point in the epithelial polarization pathway. Presumably, LKB1 may function downstream of signals received through cell-cell and cell-matrix contacts to initiate the constellation of biochemical and structural rearrangements required to produce polarity. In keeping with this interpretation, disruption of LKB1 expression suppresses the capacity of epithelial cells to polarize [16].

Previous genetic studies performed in Caenorhabditis elegans and Drosophila melanogaster indicated that the LKB1 homologues partitioning-defect 4 (Par4) and dLKB1, respectively, play essential roles in directing cell polarization during embryogenesis in these organisms $\left[17^{\bullet \bullet}, 18^{\bullet \bullet}, 19\right]$. The mechanism through which LKB1 participates in regulating cell polarity is not well understood. A series of studies have shown that this process involves the phosphorylation of microtubule-affinity-regulating kinase (MARK), a Par1 homolog, by LKB1 [19]. This phosphorylation event permits MARK to participate in interactions with other Par homologues, discussed below. A recent study, however, suggested the regulation of cell polarity is independent of the kinase activity of LKB1. In this study, mutations of LKB1 that did not disrupt LKB1 kinase activity significantly reduced LKB1-mediated activation of AMPK and compromised the ability of LKB1 to establish and maintain polarity in both intestinal epithelial cells and migrating astrocytes [16]. It appears likely, therefore, that the establishment and maintenance of cell polarity are linked, at least in part, to AMPK activation.

Since AMPK is one of the substrates of LKB1, and since energy deprivation events that activate AMPK can exert profound effects on epithelial polarity, it is interesting to speculate as to whether AMPK may be an important effector in the LKB1 polarization signaling pathway. Work from at least two groups indicates that pharmacological activation of AMPK speeds the formation of tight junctions in polarizing MDCK cells [20,21**]. Similarly, expression of a dominant-negative AMPK construct in MDCK cells profoundly slows the acquisition of mature, structurally intact junctional strands. It remains to be determined how AMPK influences junction assembly. As discussed below, the assembly of tight junctions involves interactions among a large number of protein components and presents numerous potential targets for regulatory control.

In Drosophila, disruption of the gene encoding AMPK impairs the formation of polarized plasma membrane domains in developing epithelial tissues [17*0]. Similarly, energy deprivation is sufficient to initiate Drosophila epithelial polarization [18*0. These data suggest that in the Drosophila system AMPK plays a role not only in tight junction formation but also in the formation of polarized plasma membrane domains. In fact, as discussed in detail below, the demarcation of the nascent tight junction is intimately connected to the processes that lead to epithelial polarization and the formation of biochemically differentiated plasma membrane domains.

\section{The nature of tight junctions}

The zonula occludens, or tight junction, joining neighboring epithelial cells to one another have classically been thought to perform at least three interrelated but mechanistically separable functions [22-25]. As their name implies, tight junctions form a seal that controls the nature and extent of the permeability of the paracellular pathway. Tight junctions form a barrier that blocks the diffusion of macromolecules across epithelial monolayers. This barrier also controls paracellular fluxes of both ions and water. Tight junctions can vary dramatically among epithelial tissues in both their selectivity for and resistance to different types of ionic fluxes. Finally, in the epithelial cells of vertebrates, tight junctions constitute 
the demarcation between the apical and basolateral plasma membrane domains and serve a fence function that prevents the mixing by lateral diffusion of the protein components of these two membrane compartments. Tight junctions are composed of a complicated and dynamic assembly of integral and peripheral membrane proteins. A large body of work suggests that different subsets and molecular domains of these proteins participate in determining each of these three fundamental tight junction properties [23,26-28].

The most aesthetically elegant and informative views of tight junction structure are derived from freeze fracture electron microscopy, which reveals that they are composed of circumferential parallel linear arrays of intramembranous particles that are interconnected by anastomosing perpendicular strands [29,30]. Over the past several years it has become clear that expression of members of the claudin family of membrane proteins is necessary and sufficient to generate this ultrastructural correlate of the tight junction [31]. There are at least 20 different claudins, all of which share a similar architecture consisting of four membrane spanning domains connected by a pair of small intracellular loops and a pair of larger extracellular loops [23,32]. The $\mathrm{N}$ and $\mathrm{C}$ termini are relatively short and both face the cytosol. The formation of tight junctions appears to involve interactions between the opposing claudins of neighboring cells as well as lateral interactions between adjacent claudins within a junctional strand [33]. The claudin composition of a particular tight junction determines that junction's ionic permeability and selectivity [27,34-38]. Different claudins create junctions that are differentially permeable to anions and cations.

Furthermore, claudin proteins must actually contribute to the paracellular ionic permeability pathway, as evidenced by the fact that mutations in the gene encoding the claudin protein paracellin results in loss of the paracellular permeability to magnesium ions [39]. These permeability characteristics of tight junctional claudins appear to be subject to dynamic regulation. Through mechanisms that have yet to be elucidated, the expression of wild type and mutant forms of the WNK kinases alter the anion versus cation selectivity properties of tight junctions in MDCK cells [40].

Two other transmembrane proteins also participate in the intercellular associations that contribute to the formation of tight junctions. Occludin shares the overall structural topology of the claudins [25], characterized by four transmembrane domains and two extracellular loops. The amino acid sequences of these two classes of proteins, however, manifest no relationship to one another. Occludin interacts with peripheral components of the tight junction and contributes to the junction's fence and macromolecular barrier functions, but appears not to be involved in determining the ionic permeability characteristics of tight junctions $[26,28,41-43]$. Junction adhesion molecule (JAM) spans the membrane once and possesses two immunoglobulin loops in its extracellular domain. JAM interacts with occludin and with peripheral components of the tight junction [44,45]. While the function of JAM is not entirely clear, perturbing JAM's expression or interactions alters junctional sealing and the establishment of polarity [46-48].

As many as 40 proteins associate with the tight junction and play critical roles in its establishment and maintenance [24,49]. This list includes actin, $\alpha$-actinin and cingulin, among many others. The most important peripheral protein components of the tight junction, however, are almost certainly ZO-1, 2 and 3 [25]. ZO-1 was the first tight junction component to be isolated and characterized [50,51]. It is a member of the MAGUK family and, like its counterparts in this collection, it contains a catalytically inactive guanylate kinase (GUK) domain, a SH3 domain and three PDZ domains. Each of these domains participates in interactions that mediate ZO-1's assembly with occludin, JAM, and claudins, as well as with ten or more other junction components [49]. In addition, two unique domains (U5 and U6) that flank the GUK motif appear to be involved in important intra and intermolecular associations [52]. All of these interactions contribute to the scaffolding 
function of ZO-1 and determine both its regulation and its subcellular localization [49]. $\mathrm{ZO}-1$ is a substrate for phosphorylation and may be part of a complex containing kinases $[53,54]$. The physiological activity of ZO-1 is not restricted to its involvement with the tight junction. ZO-1 can be imported into the nucleus [55], where it regulates the expression of genes relevant to epithelial growth and differentiation by modulating the activities of transcription factors [56-58]. ZO-2 and ZO-3 are also MAGUK proteins and, like ZO-1, possess PDZ and GUK domains [59]. All three ZO proteins can interact with one another and with transmembrane components of the tight junction [49,60]. ZO-2 appears to share the capacity of ZO-1 to interact with kinases and transcription factors, and to enter the nucleus [61-63].

Although the tight junctional strands are composed of claudin and occludin membrane proteins, it is clear that these strands and the functional junctions that they correspond to can not exist in the absence of ZO-1 and ZO-2 [64,65']. In contrast, ZO-3 appears to be dispensable with respect to junction formation [66]. Simultaneous disruption of ZO-1 and ZO-2 expression in an epithelial cell line completely impedes strand formation and abrogates the assembly of functionally active junctions, although the polarized distributions of at least some membrane proteins are unperturbed [64]. Expression of either ZO-1 or ZO-2 corrects this deficit. Furthermore, expression of a chimeric ZO-1 molecule containing a motif that misdirects this protein to the lateral membrane results in the generation of ectopic junctional strands throughout the lateral plasma membrane. Thus, ZO-1 or ZO-2 are required both to organize the transmembrane components of the tight junction into their distinctive linear assemblies and to target these assemblies to their proper location at the apical margin of the basolateral plasmalemma. Any mechanism that regulates tight junction assembly, therefore, must of necessity involve regulation of the localization and deposition of ZO-1 and 2.

\section{Protein complexes involved in junction formation and polarization}

Our current understanding of the mechanisms through which epithelial cells create junctions and polarized domains has been reshaped by a recent convergence of insights gleaned from experimental systems that share with epithelial cells the capacity to generate and build upon an asymmetry. These systems are phylogenetically and functionally wildly diverse, and include budding yeast, the oocytes of C. elegans, the developing epithelia of Drosophila embryos and migrating neutrophils. What these very different cell types all possess in common is the need to designate a boundary that will come to divide two morphologically and biochemically distinct domains of their surface membranes. Remarkably, very similar schemes are brought to bear in order to accomplish this function in each of these settings. Furthermore, a highly conserved set of protein complexes appears to exploit the establishment of this boundary in order produce the requisite division of a previously isotropic plasmalemma into two contiguous but fully segregated membranous organelles $[3,59,67]$.

One of these complexes consists of three proteins, which first came to attention in the context of their roles in the partitioning of the $C$. elegans oocyte into asymmetric cellular domains [3,67]. Par3 and Par6 are both PDZ domain-containing scaffolding proteins that can each interact with the third component of this complex, atypical protein kinase $\mathrm{C}$ (aPKC). A large body of evidence strongly suggests that the Par3/Par6/aPKC complex is an obligate participant in the initial polarization of epithelial cells and in the formation of interepithelial cell occluding junctions. Par3 is required for epithelial polarization in Drosophila [68], and knockdown of Par3 expression in the MDCK line of canine renal epithelial cells dramatically perturbs tight junction formation [69]. Furthermore, overexpression of Par6 or portions of the Par6 protein in MDCK cells similarly perturbs tight junction formation. 
While in Drosophila epithelial cells the Par3/Par6/aPKC complex is localized at the apical plasma membrane domain [68], in mammalian epithelial cells this complex is restricted to the region of the zonula occludens [70]. Deposition of the Par3/Par6/aPKC complex appears to determine the distribution of two other protein assemblies, the scribble group (scribble, Dlg and Lgl) and the Crumbs/PALS/PATJ complex, which collaborate to establish the identities of the basolateral and apical plasma membrane domains, respectively. These two complexes, in association with the Par3/Par6/aPKC complex, participate in complicated, mutually antagonistic interactions that result in the maintenance of stable apical and basolateral surfaces through processes involving dynamic competition [71-76].

Under normal circumstances, the acquisition of the fully polarized state is initiated by the formation of contacts between neighboring epithelial cells $\left[77^{\circ}, 78\right]$. These contacts are mediated by the calcium-dependent adhesion molecule E-cadherin $\left[77^{\circ}, 79,80\right]$ and are followed quickly by the initiation of tight junction assembly, which then instigates the events described in the preceding paragraphs. While epithelial cells require the participation of E-cadherin in order to establish the polarized state, the continued expression of this protein is apparently not required to maintain polarity in a fully polarized monolayer [ $\left.81^{* *}\right]$. This surprising observation suggests that a signal generated as a consequence of E-cadherindriven contact is required to establish polarity, and furthermore that this signal or its downstream effects can, at least under certain circumstances, become self-sustaining even in the absence of continued input from E-cadherin.

As noted above, constitutive activation of LKB1 can induce polarization of epithelial cells in the absence of cell-cell contact [15]. Similarly, activation of AMPK, a downstream effector of LKB1, by energy deprivation is sufficient to induce polarization in Drosophila epithelial cells $\left[18^{\circ}\right]$. A critical question that will no doubt drive epithelial polarity research in the near future relates to whether the complexes and machinery described above are involved in the mechanisms through which AMPK activity influences epithelial polarization (Fig. 2). In the Drosophila system, activation of AMPK leads to phosphorylation of nonmuscle myosin regulatory light chain (MRLC). Expression of a mutated form of MRLC in which the serine and threonine residues phosphorylated by AMPK are replaced by 'phosphomimic' glutamate residues is able to rescue epithelial polarization in the context of inactivating mutations in either AMPK or LKB1 [17*0]. These data suggest, therefore, that AMPK phosphorylation of MRLC is necessary and sufficient to induce epithelial polarization and that it is through MRLC that the activities of LKB1 and AMPK converge to initiate and sustain the polarized state. It will be interesting, important and exciting to determine whether the signaling cascade that leads to MRLC phosphorylation influences and is influenced by the formation of the protein complexes described above, which clearly play such critical roles in establishing and defining the biochemical identities of differentiated membrane domains.

\section{Conclusion}

Tight junctions are critically important constituents of polarized epithelial cells. The formation of tight junctions is an early step in the chain of events that leads to epithelial polarization. Tight junctions are complicated multiprotein assemblies. Their formation and localization is dependent upon intricate cooperative and competitive interrelationships among several protein complexes. Through their positive and negative interactions, these complexes appear to establish the biochemical identity of epithelial membrane domains and to determine the positioning of junctional assemblies. Recent data indicate that a new signaling pathway involved in sensing and responding to changes in cellular energy levels is also involved in establishing and maintaining polarity. Activation of LKB1 and AMPK are necessary and sufficient to initiate aspects of epithelial polarization. Future research will be 
required to elucidate the nature of the cross-talk between this signaling pathway and the formation of the protein complexes that generate the polarized state.

\section{Acknowledgments}

The authors wish to thank Drs. Lawrence Young and Lloyd Cantley as well as past and present members of the Caplan laboratory for their thoughtful comments and helpful discussions. Work from the authors' laboratory discussed in this review was supported by NIH grants DK-17433 and DK-072614.

\section{References and recommended reading}

Papers of particular interest, published within the annual period of review, have been highlighted as:

- of special interest

•• of outstanding interest

Additional references related to this topic can also be found in the Current World Literature section in this issue (pp. 000-000).

1. Caplan MJ. Membrane polarity in epithelial cells: protein sorting and establishment of polarized domains. Am J Physiol Renal Physiol 1997;272:F425-F429.

2. Muth TR, Caplan MJ. Transport protein trafficking in polarized cells. Annu Rev Cell Dev Biol 2003;19:333-366. [PubMed: 14570573]

3. Macara IG. Parsing the polarity code. Nat Rev Mol Cell Biol 2004;5:220-231. [PubMed: 14991002]

4. Yeaman C, Grindstaff KK, Nelson WJ. New perspectives on mechanisms involved in generating epithelial cell polarity. Physiol Rev 1999;79:73-98. [PubMed: 9922368]

5. Drubin DG, Nelson WJ. Origins of cell polarity. Cell 1996;84:335-344. [PubMed: 8608587]

6. Fish EM, Molitoris BA. Alterations in epithelial polarity and the pathogenesis of disease states. N Engl J Med 1994;330:1580-1588. [PubMed: 8177249]

7. Molitoris BA, Wilson PD, Schrier RW, Simon FR. Ischemia induces partial loss of surface membrane polarity and accumulation of putative calcium ionophores. J Clin Invest 1985;76:20972105. [PubMed: 3001141]

8•. Hardie DG. AMP-activated/SNF1 protein kinases: conserved guardians of cellular energy. Nat Rev Mol Cell Biol 2007;8:774-785. This is an excellent review of the functions of AMPK and its related kinases. [PubMed: 17712357]

9•. Hardie DG, Sakamoto K. AMPK: a key sensor of fuel and energy status in skeletal muscle. Physiology (Bethesda) 2006;21:48-60. This is an excellent review of the muscle-specific functions in which AMPK participates. [PubMed: 16443822]

10. Towler MC, Hardie DG. AMP-activated protein kinase in metabolic control and insulin signaling. Circ Res 2007;100:328-341. [PubMed: 17307971]

11. Suter M, Riek U, Tuerk R. Dissecting the role of 5'-AMP for allosteric stimulation, activation, and deactivation of AMP-activated protein kinase. J Biol Chem 2006;281:32207-32216. [PubMed: 16943194]

12. Shaw RJ, Kosmatka M, Bardeesy N. The tumor suppressor LKB1 kinase directly activates AMPactivated kinase and regulates apoptosis in response to energy stress. Proc Natl Acad Sci U S A 2004;101:3329-3335. [PubMed: 14985505]

13. Bardeesy N, Sinha M, Hezel AF. Loss of the Lkb1 tumour suppressor provokes intestinal polyposis but resistance to transformation. Nature 2002;419:162-167. [PubMed: 12226664]

14. Shaw RJ, Bardeesy N, Manning BD. The LKB1 tumor suppressor negatively regulates mTOR signaling. Cancer Cell 2004;6:91-99. [PubMed: 15261145]

15. Baas AF, Kuipers J, van der Wel NN. Complete polarization of single intestinal epithelial cells upon activation of LKB1 by STRAD. Cell 2004;116:457-466. [PubMed: 15016379] 
16. Forcet C, Etienne-Manneville S, Gaude H. Functional analysis of Peutz-Jeghers mutations reveals that the LKB1 C-terminal region exerts a crucial role in regulating both the AMPK pathway and the cell polarity. Hum Mol Genet 2005;14:1283-1292. [PubMed: 15800014]

17••. Lee JH, Koh H, Kim M. Energy-dependent regulation of cell structure by AMP-activated protein kinase. Nature 2007;447:1017-1020. This paper shows that in Drosophila activation of AMPK leads to phosphorylation of MRLC, and this phosphorylation appears to be necessary and sufficient to establish epithelial polarity. [PubMed: 17486097]

18••. Mirouse V, Swick LL, Kazgan N. LKB1 and AMPK maintain epithelial cell polarity under energetic stress. J Cell Biol 2007;177:387-392. In this paper the effects of AMPK mutations are examined in Drosophila. Loss of AMPK activity leads to loss of epithelial polarity under conditions of energy stress. [PubMed: 17470638]

19. Baas AF, Smit L, Clevers H. LKB1 tumor suppressor protein: PARtaker in cell polarity. Trends Cell Biol 2004;14:312-319. [PubMed: 15183188]

20. Zhang L, Li J, Young LH, Caplan MJ. AMP-activated protein kinase regulates the assembly of epithelial tight junctions. Proc Natl Acad Sci U S A 2006;103:17272-17277. [PubMed: 17088526]

$21 \bullet$. Zheng B, Cantley LC. Regulation of epithelial tight junction assembly and disassembly by AMPactivated protein kinase. Proc Natl Acad Sci U S A 2007;104:819-822. This paper shows that AMPK is activated by stimuli that initiate tight junction formation and that activation of AMPK accelerates the formation of epithelial tight junctions. [PubMed: 17204563]

22. Matter K, Aijaz S, Tsapara A, Balda MS. Mammalian tight junctions in the regulation of epithelial differentiation and proliferation. Curr Opin Cell Biol 2005;17:453-458. [PubMed: 16098725]

23. Van Itallie CM, Anderson JM. The molecular physiology of tight junction pores. Physiology (Bethesda) 2004;19:331-338. [PubMed: 15546850]

24. Aijaz S, Balda MS, Matter K. Tight junctions: molecular architecture and function. Int Rev Cytol 2006;248:261-298. [PubMed: 16487793]

25. Mitic LL, Anderson JM. Molecular architecture of tight junctions. Annu Rev Physiol 1998;60:121-142. [PubMed: 9558457]

26. Balda MS, Whitney JA, Flores C. Functional dissociation of paracellular permeability and transepithelial electrical resistance and disruption of the apical-basolateral intramembrane diffusion barrier by expression of a mutant tight junction membrane protein. J Cell Biol 1996;134:1031-1049. [PubMed: 8769425]

27. Colegio OR, Van Itallie C, Rahner C, Anderson JM. Claudin extracellular domains determine paracellular charge selectivity and resistance but not tight junction fibril architecture. Am J Physiol Cell Physiol 2003;284:C1346-C1354. [PubMed: 12700140]

28. Tokunaga Y, Kojima T, Osanai M. A novel monoclonal antibody against the second extracellular loop of occludin disrupts epithelial cell polarity. J Histochem Cytochem 2007;55:735-744. [PubMed: 17371936]

29. Hastings RA 2nd, Enders AC. Junctional complexes in the preimplantation rabbit embryo. Anat Rec 1975;181:17-33. [PubMed: 45878]

30. Cereijido M, Meza I, Martinez-Palomo A. Occluding junctions in cultured epithelial monolayers. Am J Physiol Cell Physiol 1981;240:C96-C102.

31. Furuse M, Sasaki H, Fujimoto K, Tsukita S. A single gene product, claudin-1 or -2, reconstitutes tight junction strands and recruits occludin in fibroblasts. J Cell Biol 1998;143:391-401. [PubMed: 9786950]

32. Morita K, Furuse M, Fujimoto K, Tsukita S. Claudin multigene family encoding fourtransmembrane domain protein components of tight junction strands. Proc Natl Acad Sci U S A 1999;96:511-516. [PubMed: 9892664]

33. Furuse M, Sasaki H, Tsukita S. Manner of interaction of heterogeneous claudin species within and between tight junction strands. J Cell Biol 1999;147:891-903. [PubMed: 10562289]

34. Kiuchi-Saishin Y, Gotoh S, Furuse M. Differential expression patterns of claudins, tight junction membrane proteins, in mouse nephron segments. J Am Soc Nephrol 2002;13:875-886. [PubMed: 11912246] 
35. Furuse M, Furuse K, Sasaki H, Tsukita S. Conversion of zonulae occludentes from tight to leaky strand type by introducing claudin-2 into Madin-Darby canine kidney I cells. J Cell Biol 2001;153:263-272. [PubMed: 11309408]

36. Van Itallie C, Rahner C, Anderson JM. Regulated expression of claudin-4 decreases paracellular conductance through a selective decrease in sodium permeability. J Clin Invest 2001;107:13191327. [PubMed: 11375422]

37. Colegio OR, Van Itallie CM, McCrea HJ. Claudins create charge-selective channels in the paracellular pathway between epithelial cells. Am J Physiol Cell Physiol 2002;283:C142-147. [PubMed: 12055082]

38. Holmes JL, Van Itallie CM, Rasmussen JE, Anderson JM. Claudin profiling in the mouse during postnatal intestinal development and along the gastrointestinal tract reveals complex expression patterns. Gene Expr Patterns 2006;6:581-588. [PubMed: 16458081]

39. Simon DB, Lu Y, Choate KA. Paracellin-1, a renal tight junction protein required for paracellular Mg2+ resorption. Science 1999;285:103-106. [PubMed: 10390358]

40. Kahle KT, Macgregor GG, Wilson FH. Paracellular Cl- permeability is regulated by WNK4 kinase: insight into normal physiology and hypertension. Proc Natl Acad Sci U S A 2004;101:14877-14882. [PubMed: 15465913]

41. Saitou M, Furuse M, Sasaki H. Complex phenotype of mice lacking occludin, a component of tight junction strands. Mol Biol Cell 2000;11:4131-4142. [PubMed: 11102513]

42. Schulzke JD, Gitter AH, Mankertz J. Epithelial transport and barrier function in occludin-deficient mice. Biochim Biophys Acta 2005;1669:34-42. [PubMed: 15842997]

43. Nusrat A, Brown GT, Tom J. Multiple protein interactions involving proposed extracellular loop domains of the tight junction protein occludin. Mol Biol Cell 2005;16:1725-1734. [PubMed: 15659655]

44. Bazzoni G. The JAM family of junctional adhesion molecules. Curr Opin Cell Biol 2003;15:525530. [PubMed: 14519386]

45. Bazzoni G, Martinez-Estrada OM, Orsenigo F. Interaction of junctional adhesion molecule with the tight junction components ZO-1, cingulin, and occludin. J Biol Chem 2000;275:20520-20526. [PubMed: 10877843]

46. Liu Y, Nusrat A, Schnell FJ. Human junction adhesion molecule regulates tight junction resealing in epithelia. J Cell Sci 2000;113(Pt 13):2363-2374. [PubMed: 10852816]

47. Mandell KJ, Babbin BA, Nusrat A, Parkos CA. Junctional adhesion molecule 1 regulates epithelial cell morphology through effects on beta1 integrins and Rap1 activity. J Biol Chem 2005;280:11665-11674. [PubMed: 15677455]

48. Rehder D, Iden S, Nasdala I. Junctional adhesion molecule-a participates in the formation of apicobasal polarity through different domains. Exp Cell Res 2006;312:3389-3403. [PubMed: 16919624]

49. Schneeberger EE, Lynch RD. The tight junction: a multifunctional complex. Am J Physiol Cell Physiol 2004;286:C1213-C1228. [PubMed: 15151915]

50. Anderson JM, Stevenson BR, Jesaitis LA. Characterization of ZO-1, a protein component of the tight junction from mouse liver and Madin-Darby canine kidney cells. J Cell Biol 1988;106:11411149. [PubMed: 2452168]

51. Stevenson BR, Siliciano JD, Mooseker MS, Goodenough DA. Identification of ZO-1: a high molecular weight polypeptide associated with the tight junction (zonula occludens) in a variety of epithelia. J Cell Biol 1986;103:755-766. [PubMed: 3528172]

52. Fanning AS, Little BP, Rahner C. The unique-5 and -6 motifs of $\mathrm{ZO}-1$ regulate tight junction strand localization and scaffolding properties. Mol Biol Cell 2007;18:721-731. [PubMed: 17182847]

53. Stuart RO, Nigam SK. Regulated assembly of tight junctions by protein kinase C. Proc Natl Acad Sci U S A 1995;92:6072-6076. [PubMed: 7597083]

54. Balda MS, Anderson JM, Matter K. The SH3 domain of the tight junction protein ZO-1 binds to a serine protein kinase that phosphorylates a region $\mathrm{C}$-terminal to this domain. FEBS Lett 1996;399:326-332. [PubMed: 8985173] 
55. Gottardi CJ, Arpin M, Fanning AS, Louvard D. The junction-associated protein, zonula occludens-1, localizes to the nucleus before the maturation and during the remodeling of cell-cell contacts. Proc Natl Acad Sci U S A 1996;93:10779-10784. [PubMed: 8855257]

56. Balda MS, Garrett MD, Matter K. The ZO-1-associated Y-box factor ZONAB regulates epithelial cell proliferation and cell density. J Cell Biol 2003;160:423-432. [PubMed: 12566432]

57. Balda MS, Matter K. The tight junction protein ZO-1 and an interacting transcription factor regulate ErbB-2 expression. Embo J 2000;19:2024-2033. [PubMed: 10790369]

58. Matter K, Balda MS. Signalling to and from tight junctions. Nat Rev Mol Cell Biol 2003;4:225236. [PubMed: 12612641]

59. Shin K, Fogg VC, Margolis B. Tight junctions and cell polarity. Annu Rev Cell Dev Biol 2006;22:207-235. [PubMed: 16771626]

60. Itoh M, Furuse M, Morita K. Direct binding of three tight junction-associated MAGUKs, ZO-1, ZO-2, and ZO-3, with the COOH termini of claudins. J Cell Biol 1999;147:1351-1363. [PubMed: 10601346]

61. Avila-Flores A, Rendon-Huerta E, Moreno J. Tight-junction protein zonula occludens 2 is a target of phosphorylation by protein kinase C. Biochem J 2001;360:295-304. [PubMed: 11716757]

62. Betanzos A, Huerta M, Lopez-Bayghen E. The tight junction protein ZO-2 associates with Jun, Fos and C/EBP transcription factors in epithelial cells. Exp Cell Res 2004;292:51-66. [PubMed: 14720506]

63. Jaramillo BE, Ponce A, Moreno J. Characterization of the tight junction protein ZO-2 localized at the nucleus of epithelial cells. Exp Cell Res 2004;297:247-258. [PubMed: 15194440]

64. Umeda K, Ikenouchi J, Katahira-Tayama S. ZO-1 and ZO-2 independently determine where claudins are polymerized in tight-junction strand formation. Cell 2006;126:741-754. [PubMed: 16923393]

65•. Hernandez S, Chavez Munguia B, Gonzalez-Mariscal L. ZO-2 silencing in epithelial cells perturbs the gate and fence function of tight junctions and leads to an atypical monolayer architecture. Exp Cell Res 2007;331:1533-1547. In this interesting paper the authors explore the role of ZO-2 in tight junction function. [PubMed: 17374535]

66. Adachi M, Inoko A, Hata M. Normal establishment of epithelial tight junctions in mice and cultured cells lacking expression of ZO-3, a tight-junction MAGUK protein. Mol Cell Biol 2006;26:9003-9015. [PubMed: 17000770]

67. Macara IG. Par proteins: partners in polarization. Curr Biol 2004;14:R160-R162. [PubMed: 15027470]

68. Tepass U, Tanentzapf G, Ward R, Fehon R. Epithelial cell polarity and cell junctions in Drosophila. Annu Rev Genet 2001;35:747-784. [PubMed: 11700298]

69. Chen X, Macara IG. Par-3 controls tight junction assembly through the Rac exchange factor Tiam1. Nat Cell Biol 2005;7:262-269. [PubMed: 15723052]

70. Roh MH, Margolis B. Composition and function of PDZ protein complexes during cell polarization. Am J Physiol Renal Physiol 2003;285:F377-387. [PubMed: 12890661]

71. Tanentzapf G, Tepass U. Interactions between the crumbs, lethal giant larvae and bazooka pathways in epithelial polarization. Nat Cell Biol 2003;5:46-52. [PubMed: 12510193]

72. Bilder D, Schober M, Perrimon N. Integrated activity of PDZ protein complexes regulates epithelial polarity. Nat Cell Biol 2003;5:53-58. [PubMed: 12510194]

73. Musch A, Cohen D, Yeaman C. Mammalian homolog of Drosophila tumor suppressor lethal (2) giant larvae interacts with basolateral exocytic machinery in Madin-Darby canine kidney cells. Mol Biol Cell 2002;13:158-168. [PubMed: 11809830]

74. Yamanaka T, Horikoshi Y, Sugiyama Y. Mammalian Lgl forms a protein complex with PAR-6 and aPKC independently of PAR-3 to regulate epithelial cell polarity. Curr Biol 2003;13:734-743. [PubMed: 12725730]

75. Plant PJ, Fawcett JP, Lin DC. A polarity complex of mPar-6 and atypical PKC binds, phosphorylates and regulates mammalian Lgl. Nat Cell Biol 2003;5:301-308. [PubMed: 12629547]

76. Hurd TW, Gao L, Roh MH. Direct interaction of two polarity complexes implicated in epithelial tight junction assembly. Nat Cell Biol 2003;5:137-142. [PubMed: 12545177] 
77•. Nejsum LN, Nelson WJ. A molecular mechanism directly linking E-cadherin adhesion to initiation of epithelial cell surface polarity. J Cell Biol 2007;178:323-335. This manuscript describes interesting experiments demonstrating that the formation of E-cadherin mediated cellcell contacts is sufficient to initiate the establishment of the identity of the basolateral membrane domain. [PubMed: 17635938]

78. Nelson WJ, Veshnock PJ. Modulation of fodrin (membrane skeleton) stability by cell-cell contact in Madin-Darby canine kidney epithelial cells. J Cell Biol 1987;104:1527-1537. [PubMed: 3584240]

79. Gumbiner B, Simons K. A functional assay for proteins involved in establishing an epithelial occluding barrier: identification of a uvomorulin-like polypeptide. J Cell Biol 1986;102:457-468. [PubMed: 3511070]

80. Gumbiner B, Stevenson B, Grimaldi A. The role of the cell adhesion molecule uvomorulin in the formation and maintenance of the epithelial junctional complex. J Cell Biol 1988;107:1575-1587. [PubMed: 3049625]

81••. Capaldo CT, Macara IG. Depletion of E-cadherin disrupts establishment but not maintenance of cell junctions in Madin-Darby canine kidney epithelial cells. Mol Biol Cell 2007;18:189-200. This paper presents the very surprising observation that E-cadherin is required for the establishment but not for the maintenance of epithelial polarity. [PubMed: 17093058] 


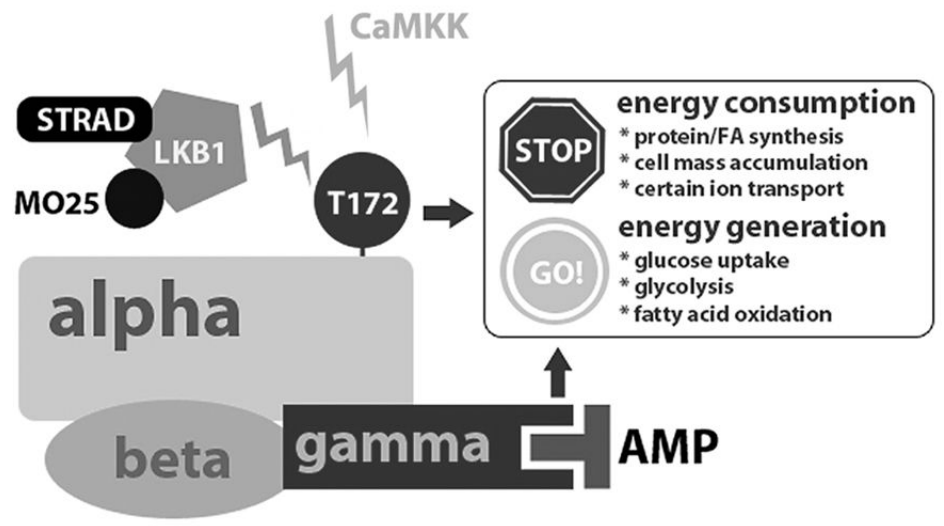

Figure 1. AMPK is activated by upstream kinases and serves to regulate energy utilization and production pathways

AMPK is a trimeric complex made up of $\alpha, \beta$ and $\gamma$-subunits. Binding of AMP by the $\gamma$ subunit causes the $\alpha$-subunit to become a substrate for phosphorylation by upstream kinases, such as LKB1 or calmodulin kinase kinase. Once activated, AMPK serves to stimulate pathways that promote energy generation and to inhibit a variety of processes that consume energy. 


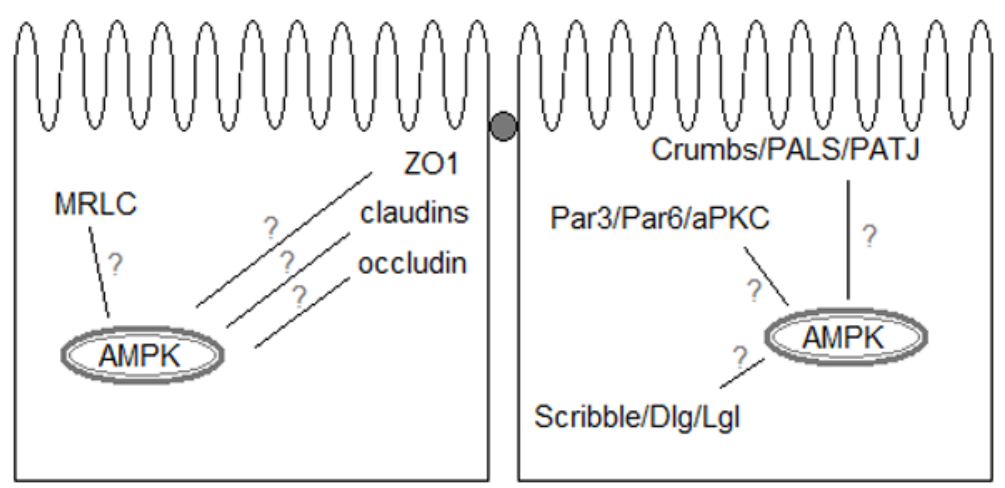

Figure 2. Activation of AMPK leads to ZO1 deposition and the initiation of polarization pathways

Initiation of epithelial contact leads to the activation of AMPK, and pharmacological activation of AMPK is sufficient to initiate aspects of the epithelial polarization and junction formation cascades. While the precise mechanisms through which AMPK participates in these processes remain to be determined, it is possible that AMPK could exert its effects, at least in part, by affecting the assembly, activities or distributions of the enzymes and complexes depicted here. These complexes and enzymatic activites are individually described in the text. 